\title{
Preparation and Characterization of Siloxane-Imide Block Copolymers Based on 3,3',4,4'-Benzophenonetetracarboxylic Dianhydride
}

\author{
Yasuharu Yamada*, ${ }^{*}$ and Nobuyuki FuruKaWA** \\ $R \& D$ Laboratories Nippon Steel Chemical Co., Ltd., 46-80, Nakabaru Sakinohama, \\ Tobata-ku, Kitakyushu 804, Japan
}

(Received April 11, 1997)

\begin{abstract}
Siloxane-imide block copolymers with different siloxane contents and lengths based on 3,3',4,4'-benzophenonetetracarboxylic dianhydride, aromatic dianhydrides with four phenylene rings and bis( $\gamma$-aminopropyl)polydimethylsiloxane were prepared and their physical, thermal and mechanical properties were studied. The siloxane-imide block copolymer consists of a microphase separated structure of polyimide and polysiloxane phases and have two glass transition temperatures arising from polyimide and polysiloxane phases. The higher glass transition temperature $\left(T_{\mathrm{g} 2}\right)$ of the copolymer was lowered with increasing the siloxane content, while the lower $T_{\mathrm{g} 1}$ was almost independent of the siloxane content and length. The thermal decomposition temperature, tensile modulus and tensile strength of the copolymer were also lowered with increasing the siloxane content. The moisture absorption of the copolymers was very low compared with aromatic polyimides, which was almost independent of the siloxane content. The thermal expansion coefficient of the copolymer was a little increased with increasing the siloxane content up to $30 \mathrm{wt} \%$. Siloxane-imide block copolymers with desired properties can be controlled by the siloxane content and length.
\end{abstract}

KEY WORDS Siloxane-Imide Block Copolymer / Thermal Property / Mechanical Property / Siloxane Content / Siloxane Length / Microphase Separation /

Many types of polyimides have been developed and currently used in the industrial field for many applications as microelectronics coatings, adhesives and gas separation membranes. ${ }^{1-5}$ Especially, polyimides are useful materials as coatings for semiconductors in microelectronics industries and the polyimide coatings are applying as passivant, junction coating, buffer coating, and dielectric interlayer for microelectronics applications because of the high reliable properties as well as their excellent thermal, mechanical and electrical properties. ${ }^{6,7}$ On the other hand, siloxane polymers (silicone polymers) are well known useful as industrial materials and widely used for paints, coatings, electronics, sealing, cosmetics, and construction applications because of their excellent properties such as thermal stability at high and low temperature, electrical properties like insulation property and low dielectric property, good adhesion, resistance to humidity, high gas permeability, and elastisity. ${ }^{8,9}$ In addition, silicon and siloxane modified polyimides have also been developed to improve the properties such as solubility, processability, gas permeability, and electrical properties by incorporating silicon and siloxane unit into the polymer backbone ${ }^{10-14}$ and some of them have been commercially used in microelectronics applications because of their improved properties. ${ }^{15,16}$ We have reported the synthesis and characterization of some silicon and siloxane modified polyimides with improved mechanical, electrical, adhesion, and gas separation properties for microelectronics, adhesion, and membrane applications. ${ }^{17-21}$ According to the previous reports, siloxane-imide block copolyimides show several improved properties such as low tensile modulus, low dielectric constant and low water absorption due to the incorporation of siloxane moiety for microelectronics applications compared with aromatic polyimides.

In this study, three series of siloxane-imide block copolyimides were prepared and characterized based on $3,3^{\prime}, 4,4^{\prime}$-benzophenonetetracarboxylic dianhydride, three types of aromatic diamines with four phenylene rings and several types of diaminopolydimethylsiloxanes and the relation between the properties and the structures of the copolyimides were discussed.

\section{EXPERIMENTAL}

\section{Materials}

3,3',4,4'-Benzophenonetetracarboxylic dianhydride (BTDA) was obtained from Daicel Chem. Co., Ltd. (Tokyo, Japan). Three kinds of aromatic diamines, 2,2bis[4-(4-aminophenoxy)phenyl]propane (BAPP), bis[4(4-aminophenoxy)phenyl] sulfone (BAPS), and 2,2-bis[4-(4-aminophenoxy)phenyl]hexafluoropropane (BAPF) were obtained from Wakayama Seika Co., Ltd. (Wakayama, Japan). Several types of siloxane containing diamines of bis( $\gamma$-aminopropyl)tetramethylsiloxane (GAPD) and bis( $\gamma$-aminopropyl)polydimethylsiloxanes (PSX-750, 944, 1300, 2560, and 4000) with different molecular weight were obtained from Toray Dow Corning Co., Ltd. (Tokyo, Japan). $N$-Methyl-2-pyrrolidinone (NMP) and diethyleneglycol dimethylether (Diglyme) as solvents for polyimides preparation were obtained from Wako Pure Chem. Co., Ltd. (Tokyo, Japan) and Mitsubishi Chemical Co., Ltd. (Tokyo, Japan). All reagents for the study were commercially obtained and used without further purification. The monomers used in this study were summarized in Scheme 1.

\footnotetext{
* Present address: Technical Department, Nippon Steel Chemical Co., Ltd., 2-31-1, Shinkawa, Chuo-ku, Tokyo 104, Japan.

** Present address: Nippon Steel Corporation, Advanced Technology Research Laboratories, 3-35-1, Ida, Nakahara-ku, Kawasaki 211 , Japan.

$\dagger$ To whom correspondence should be addressed.
} 
Preparation of Siloxane-Imide Block Copolymers [Poly(amic acid)s $]^{20}$

The copolymers [poly(amic acid)s] were prepared from aromatic tetracarboxylic dianhydride (BTDA), aromatic diamines (BAPP, BAPS, and BAPF), and siloxane containing diamines by solution polycondensation technique. BTDA was reacted with siloxane containing diamines in NMP and Diglyme $(1: 1)$ solvent at room

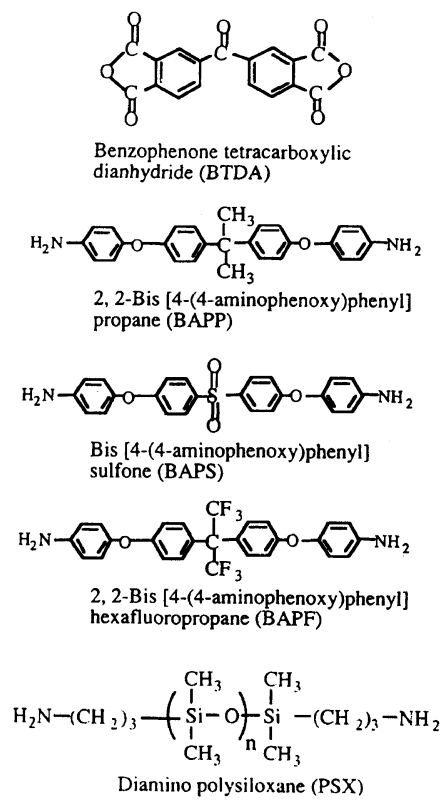

Scheme 1. Monomer components for siloxane-imide block copolymers. temperature for $2 \mathrm{~h}$ followed by the addition of aromatic diamines to react at 0 to $5^{\circ} \mathrm{C}$ for $1 \mathrm{~h}$ and at room temperature for $3 \mathrm{~h}$ to prepare the precursors [poly(amic acid)s] of siloxane-imide block copolymers. The polymer content of the solution was controlled by $20 \%$ with the solution viscosity in the range of 1000 to $3000 \mathrm{cps}$. The synthetic method was shown in Scheme 2.

\section{Preparation of Polyimide Films}

The voidless transparent polyimide films were prepared from poly(amic acid) solution by casting method. The procedure to make film is; the polymer solution was casted on glass and dried to remove the solvent at $100^{\circ} \mathrm{C}$ for $1 \mathrm{~h}$. After peeling off the polymer film from the glass, the film was fixed with stainless frame followed by heating at $180^{\circ} \mathrm{C}$ and $250^{\circ} \mathrm{C}$ for $1 \mathrm{~h}$ at each temperature to make polyimide film. Thickness of the polyimide film was controlled in the range of $25 \pm 2 \mu \mathrm{m}$.

\section{Characterization}

The properties of the polymers were characterized by infrared analysis (IR), thermogravimetric analysis (TGA), thermomechanical analysis (TMA), dynamic mechanical and mechanical measurement. The inherent viscosity was determined by a Cannon-Ubbelohde viscometer with $0.5 \mathrm{~g}$ of poly(amic acid) per $100 \mathrm{ml}$ of dimethylformamide (DMF) as solvent at $30^{\circ} \mathrm{C}$. The solution viscosity was measured by E-type rotation viscometer (Tokyo Seiki Co., Ltd.). The IR spectra of the polymers were recorded by a Hitachi IR Spectrometer 260-50 (Hitachi Co., Ltd.) using $\mathrm{KBr}$ tablets and<smiles>O=C(c1ccc2c(c1)C(=O)OC2=O)c1ccc2c(c1)C(=O)OC2=O</smiles>
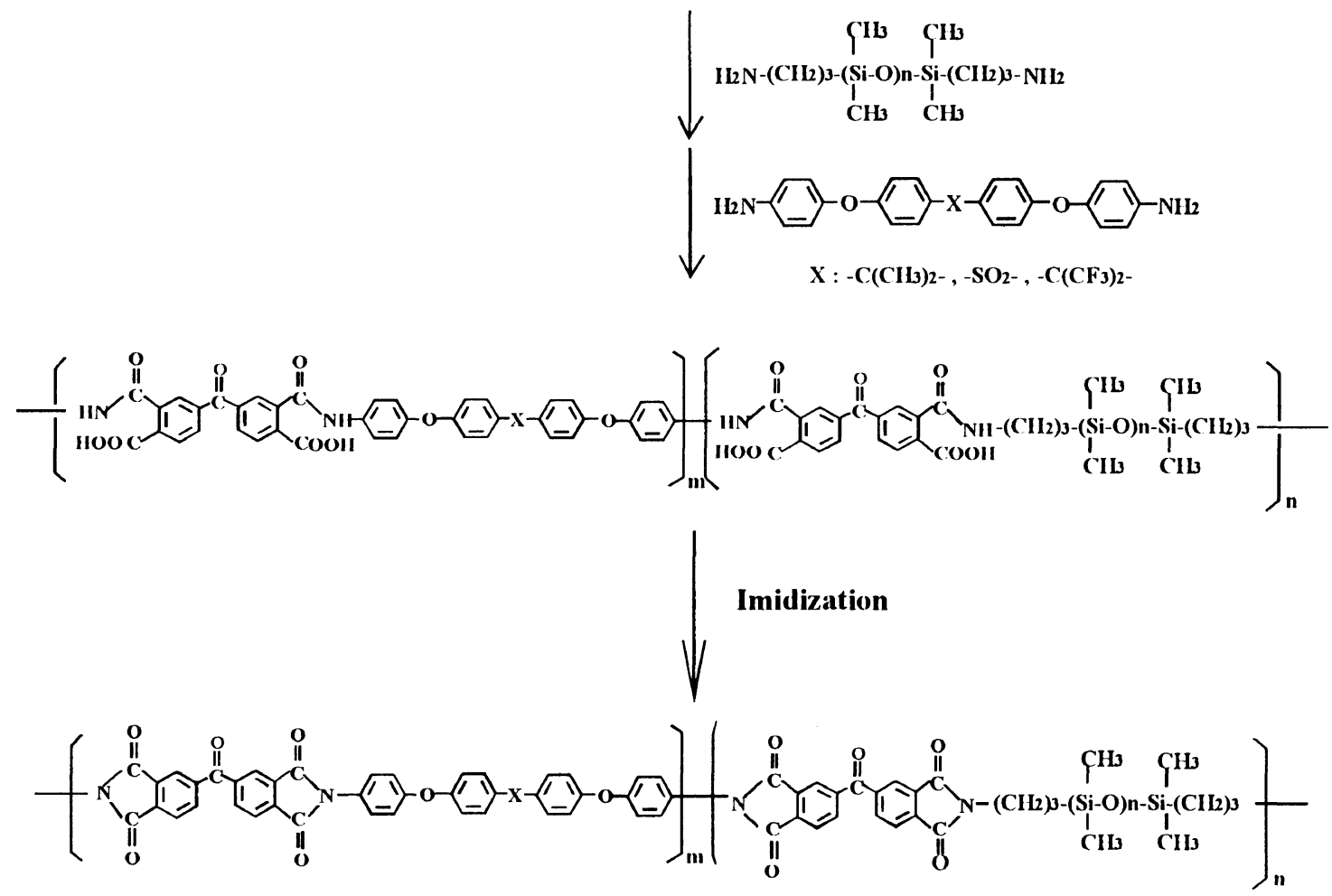

Scheme 2. Preparation method of siloxane-imide block copolymers. 
polymer films. Thermal stability of the polymers was determined by TGA as the temperature $\left(T_{\mathrm{d}}\right)$ at which $5 \%$ weight loss occurred at heating rate of $10^{\circ} \mathrm{C} \mathrm{min}^{-1}$ in a nitrogen atmosphere using a SSC 5200 Thermal Analysis System (Seiko Instruments Inc.). Thermomechanical analysis was conducted with SSC 5670 Thermal Analysis System (Seiko Instruments Inc.) at heating rate of $20^{\circ} \mathrm{C} \mathrm{min}^{-1}$ under nitrogen atmosphere. The dynamic viscoelasticity was measured by a DMS 100 Dynamic Mechanical Analyzer (DMA) and a Rheol Station SDM 5500 (Seiko Instruments Inc.) at a heating rate of $2^{\circ} \mathrm{Cmin}^{-1}$ and a frequency of $10 \mathrm{~Hz}$ in the temperature range of -150 to $300^{\circ} \mathrm{C}$. The mechanical properties such as tensile modulus, tensile strength, and elongation were measured by an Autograph AG-500A (Shimadzu Co., Ltd.) at a drawing rate of $5 \mathrm{~mm} \mathrm{~min}^{-1}$ at room temperature. Imidization degree was determined from IR spectrum of each polymer of which absorption peak at $1780 \mathrm{~cm}^{-1}$ is used as a criteria of the degree of imidization. Moisture adsorption was determined by measurement of the weight increase of the polymer film after the treatment at $23^{\circ} \mathrm{C}, 78 \% \mathrm{RH}$ for $24 \mathrm{~h}$. Dielectric constant of the polymers were determined with polymer films using a Hewlett-Packard 4192A LF impedance Analyzer at frequency of $1 \mathrm{KHz}$ and $1 \mathrm{MHz}$ according to the test method of ASTM D-150.

Table I. Preparation of siloxane-imide block copolymers

\begin{tabular}{|c|c|c|c|c|c|c|}
\hline \multirow{2}{*}{$\begin{array}{c}\text { Polymer } \\
\text { No. }\end{array}$} & \multicolumn{6}{|c|}{ Monomer composition (mol ratio) } \\
\hline & \multicolumn{2}{|c|}{ Dianhydride } & \multicolumn{2}{|c|}{ Aromatic diamine } & \multicolumn{2}{|c|}{ Siloxane diamine } \\
\hline A-1 & & & & 1.0 & & 0 \\
\hline A-2 & BTDA & 1.0 & BAPP & 0.937 & PSX-1300 & 0.063 \\
\hline A-3 & & & & 0.82 & & 0.18 \\
\hline A-4 & & & & 0.68 & & 0.32 \\
\hline B-1 & & & & 1.0 & & 0 \\
\hline B-2 & BTDA & 1.0 & BAPS & 0.935 & PSX-1300 & 0.065 \\
\hline B-3 & & & & 0.82 & & 0.18 \\
\hline B-4 & & & & 0.67 & & 0.33 \\
\hline $\mathrm{C}-1$ & & & & 1.0 & & 0 \\
\hline $\mathrm{C}-2$ & BTDA & 1.0 & BAPF & 0.928 & PSX-1300 & 0.072 \\
\hline $\mathrm{C}-3$ & & & & 0.80 & & 0.20 \\
\hline C-4 & & & & 0.65 & & 0.35 \\
\hline
\end{tabular}

\section{RESULTS AND DISCUSSION}

Three types of siloxane-imide block copolymers with different siloxane contents $(0,10,25$, and $40 \mathrm{wt} \%)$ were prepared from BTDA, PSX-1300, and BAPP, BAPS, and BAPF as aromatic diamines and characterized. Siloxaneimide block copolymers based on BTDA, BAPP, and siloxane containing diamines with different siloxane lengths were also prepared and characterized.

Three types of copolymers prepared are;

Type A: BTDA/BAPP/PSX-1300

Type B: BTDA/BAPS/PSX-1300

Type C: BTDA/BAPF/PSX-1300

The polymerization condition and the properties of three types of copolymers were summarized in Tables I to III, respectively.

\section{Thermal and Mechanical Properties}

The effects of siloxane contents on thermal and mechanical properties in three types of copolymers were shown in Figures 1 to 6.

Siloxane-imide block copolymers possessed two different glass transition temperatures $\left(T_{\mathrm{g}} \mathrm{s}\right)$ derived from siloxane and aromatic polyimide segments. Lower glass transition temperature $\left(T_{\mathrm{g} 1}\right)$ at about $-120^{\circ} \mathrm{C}$ derived from siloxane segment was almost independent of the siloxane content, while higher glass transition temperature $\left(T_{\mathrm{g} 2}\right)$ derived from aromatic polyimide segment significantly dropped with the increase of siloxane content. This indicates that siloxane dissolves in the aromatic polyimide phase to some extent with the increase of siloxane content, which was supported by DMA discussed later. Thermal decomposition temperatures $\left(T_{\mathrm{d}} \mathrm{s}\right)$ of the copolymers also dropped with the increase of siloxane content as well as $T_{\mathrm{g} 2}$. However, $T_{\mathrm{d}} \mathrm{s}$ of the copolymers for types A and B were almost independent of siloxane content in more than $30 \mathrm{wt} \%$ of siloxane content. The order of $T_{\mathrm{d}}$ and $T_{\mathrm{g} 2}$ were Type $\mathrm{B} \cong$ Type $\mathrm{C}>$ Type $\mathrm{A}$ for $T_{\mathrm{d}}$ and Type $\mathrm{B}>$ Type $\mathrm{C}>$ Type $\mathrm{A}$ for $T_{\mathrm{g} 2}$. Thermal expansion coefficients (CTEs) of the copolymers at the temperature range of 25 to $100^{\circ} \mathrm{C}$ were almost independent of the siloxane content in the range of 0 to $25 \mathrm{wt} \%$ but significantly increased with the increase of siloxane content in more than $25 \mathrm{wt} \%$ for

Table II. Physical and thermal properties of siloxane-imide block copolymers

\begin{tabular}{|c|c|c|c|c|c|c|}
\hline \multirow{2}{*}{$\begin{array}{c}\text { Polymer } \\
\text { No. }\end{array}$} & \multirow{2}{*}{$\frac{\eta_{\mathrm{inh}}}{\mathrm{g} \mathrm{dl}^{-1}}$} & \multirow{2}{*}{$\frac{T_{\mathrm{g}}}{{ }^{\circ} \mathrm{C}}$} & \multirow{2}{*}{$\begin{array}{l}T_{\mathrm{d}} \\
{ }^{\circ} \mathrm{C}\end{array}$} & \multicolumn{2}{|c|}{$\begin{array}{l}\text { Thermal expansion } \\
\text { coefficient } / \mathrm{ppm}^{\circ} \mathrm{C}^{-1}\end{array}$} & \multirow{2}{*}{$\begin{array}{c}\begin{array}{c}\text { Moisture } \\
\text { absorption }\end{array} \\
\%\end{array}$} \\
\hline & & & & $25-100^{\circ} \mathrm{C}$ & $100-150^{\circ} \mathrm{C}$ & \\
\hline A-1 & 1.09 & 213 & 493 & 21 & 25 & 1.02 \\
\hline A-2 & 0.65 & 207 & 481 & 23 & 28 & 0.32 \\
\hline A-3 & 0.52 & 185 & 462 & 28 & 65 & 0.27 \\
\hline A-4 & 0.32 & 159 & 457 & 55 & 128 & 0.25 \\
\hline B-1 & 0.85 & 255 & 539 & 26 & 28 & 1.04 \\
\hline B-2 & 0.50 & 240 & 505 & 29 & 31 & 0.29 \\
\hline B-3 & 0.30 & 213 & 466 & 34 & 70 & 0.26 \\
\hline B-4 & 0.28 & 171 & 459 & 52 & 125 & 0.27 \\
\hline C-1 & 0.87 & 208 & 539 & 19 & 23 & 0.40 \\
\hline $\mathrm{C}-2$ & 0.30 & 207 & 498 & 27 & 38 & 0.25 \\
\hline C-3 & 0.25 & 176 & 468 & 42 & 81 & 0.24 \\
\hline C-4 & 0.22 & 130 & 448 & 58 & 160 & 0.21 \\
\hline
\end{tabular}


Table III. Mechanical properties of siloxane-imide block copolymers

\begin{tabular}{|c|c|c|c|}
\hline \multirow{2}{*}{$\begin{array}{c}\text { Polymer } \\
\text { No. }\end{array}$} & $\begin{array}{l}\text { Tensile } \\
\text { modulus }\end{array}$ & $\begin{array}{l}\text { Tensile } \\
\text { strength }\end{array}$ & \multirow{2}{*}{$\frac{\text { Elongation }}{\%}$} \\
\hline & $\mathrm{GPa}$ & $\mathrm{MPa}$ & \\
\hline A-1 & 2.86 & 103.0 & 7.1 \\
\hline A-2 & 2.11 & 82.4 & 7.1 \\
\hline A-3 & 1.46 & 50.0 & 18.0 \\
\hline A-4 & 0.34 & 22.6 & 35.0 \\
\hline B-1 & 2.70 & 125.5 & 9.3 \\
\hline B-2 & 1.93 & 95.1 & 9.1 \\
\hline B-3 & 1.23 & 53.9 & 13.5 \\
\hline B-4 & 0.37 & 30.4 & 50.7 \\
\hline C-1 & 2.28 & 105.9 & 9.0 \\
\hline C-2 & 1.92 & 83.4 & 10.0 \\
\hline C-3 & 1.49 & 64.7 & 10.5 \\
\hline C-4 & 0.44 & 26.7 & 48.8 \\
\hline
\end{tabular}

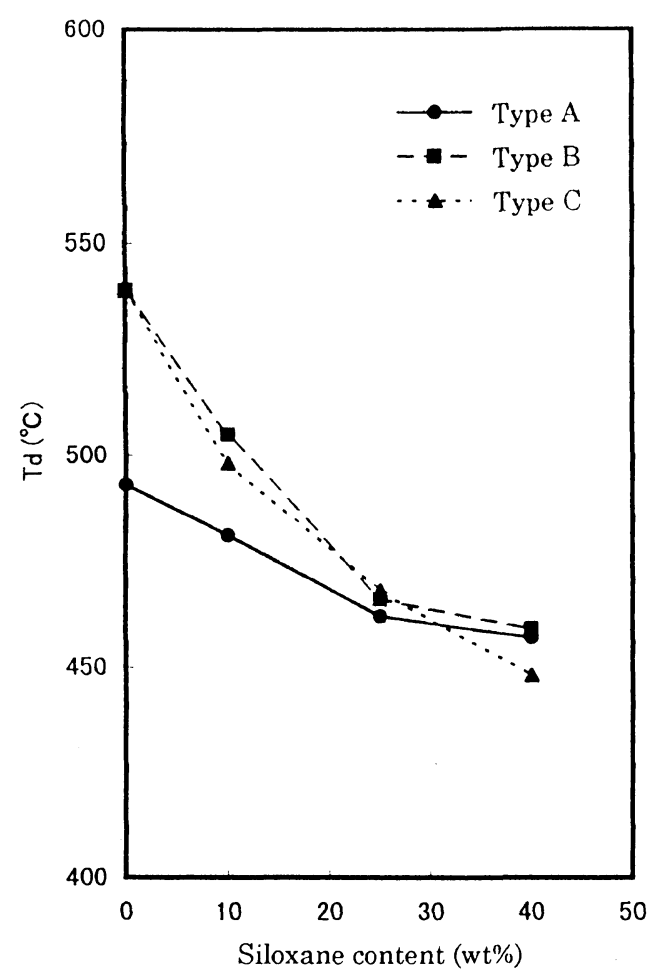

Figure 1. Relationship between thermal decomposition temperature and siloxane content.

Type A and B. In contrast, CTE of the copolymers for Type $\mathrm{C}$ was linearly increased with the increase of siloxane content, in spite of the lowest CTE in C-1 (Figure 3).

The mechanical properties such as tensile modulus (TM) and tensile strength (TS) linearly lowered with increasing the siloxane content, and there were no significant differences between three types of copolymers.

Elongation (EL), however, significantly increased in the copolymers with $40 \mathrm{wt} \%$ of siloxane content, which showed elastic behavior. On the other hand, ELs of the copolymers with less than $25 \mathrm{wt} \%$ of siloxane content are almost independent of the contents. This indicates siloxane-imide block copolymers with low CTEs can be obtained in the range of less than $25 \mathrm{wt} \%$ of siloxane content.

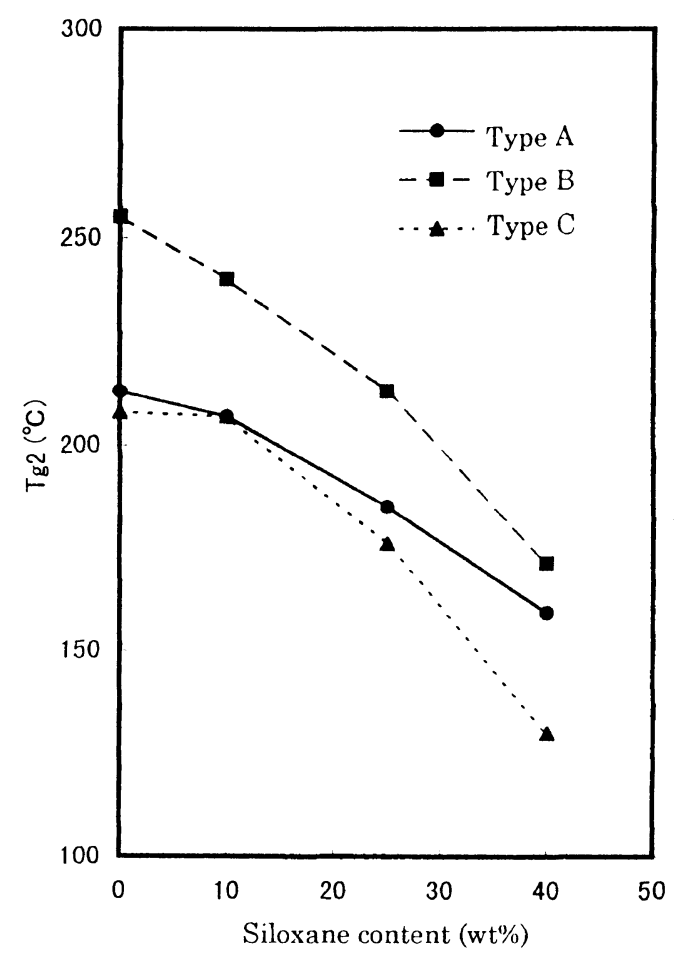

Figure 2. Relationship between glass transition temperature $\left(T_{\mathrm{g} 2}\right)$ and siloxane content.

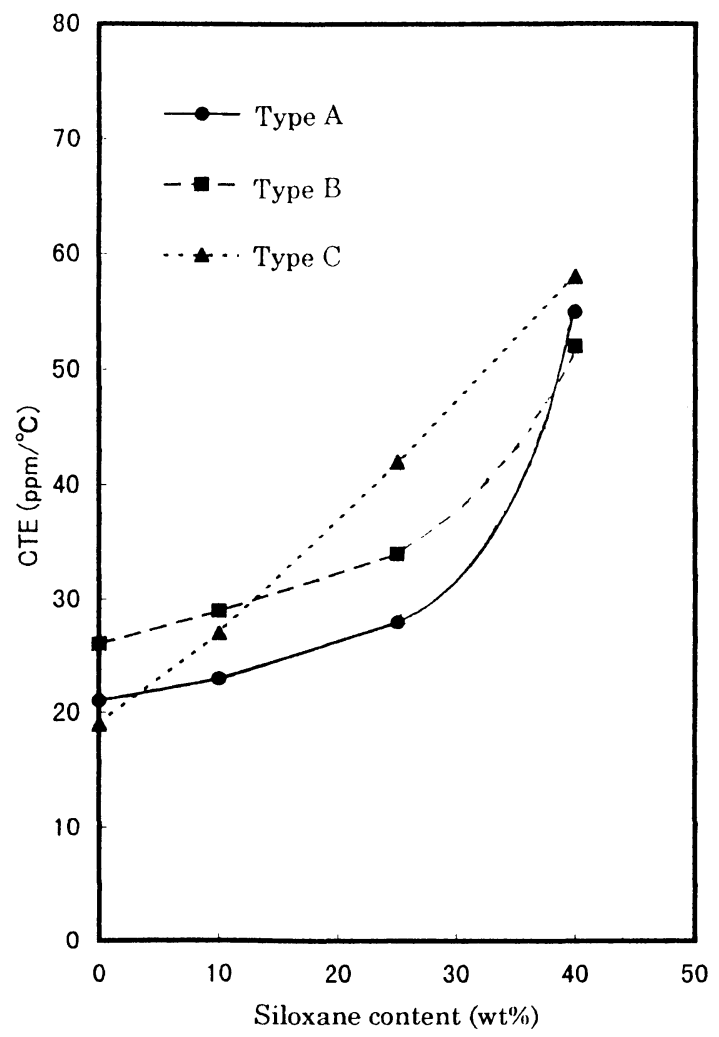

Figure 3. Relationship between thermal expansion coefficient and siloxane content (temperature range, 25 to $100^{\circ} \mathrm{C}$ ).

\section{Dynamic Mechanical Analysis}

The temperature dependence of storage modulus $\left(E^{\prime}\right)$, loss modulus $\left(E^{\prime \prime}\right)$, and loss tangent $(\tan \delta)$ for Type A copolymer films was shown in Figure 7. Two peaks were observed in the $E^{\prime \prime}$ and $\tan \delta$ curves for siloxane-imide block copolymers, while only one peak was observed for 


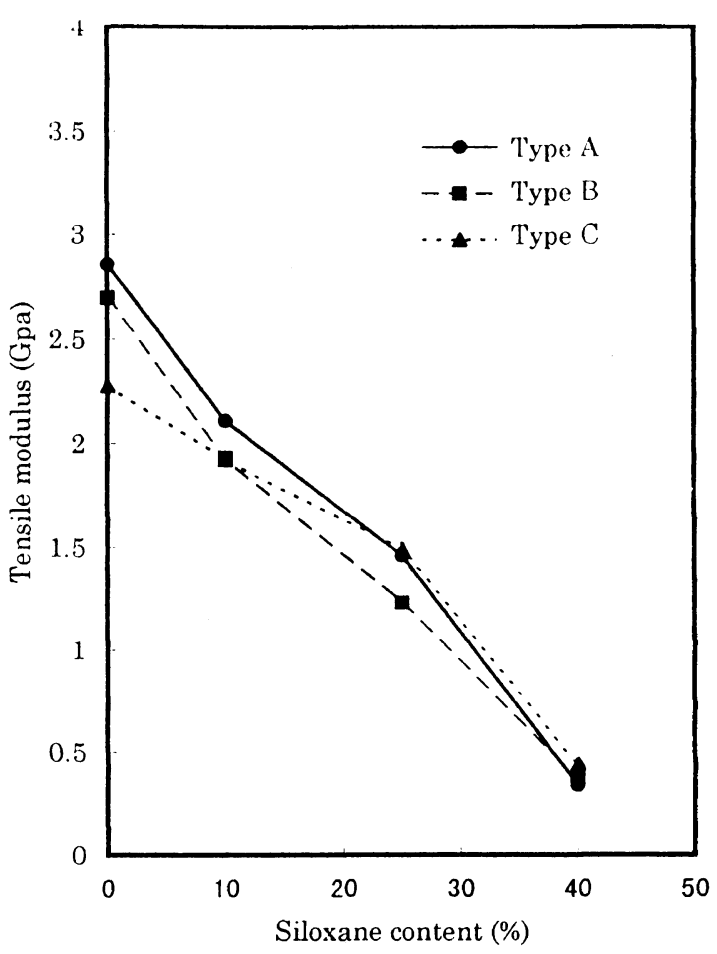

Figure 4. Relationship between tensile modulus and siloxane content.

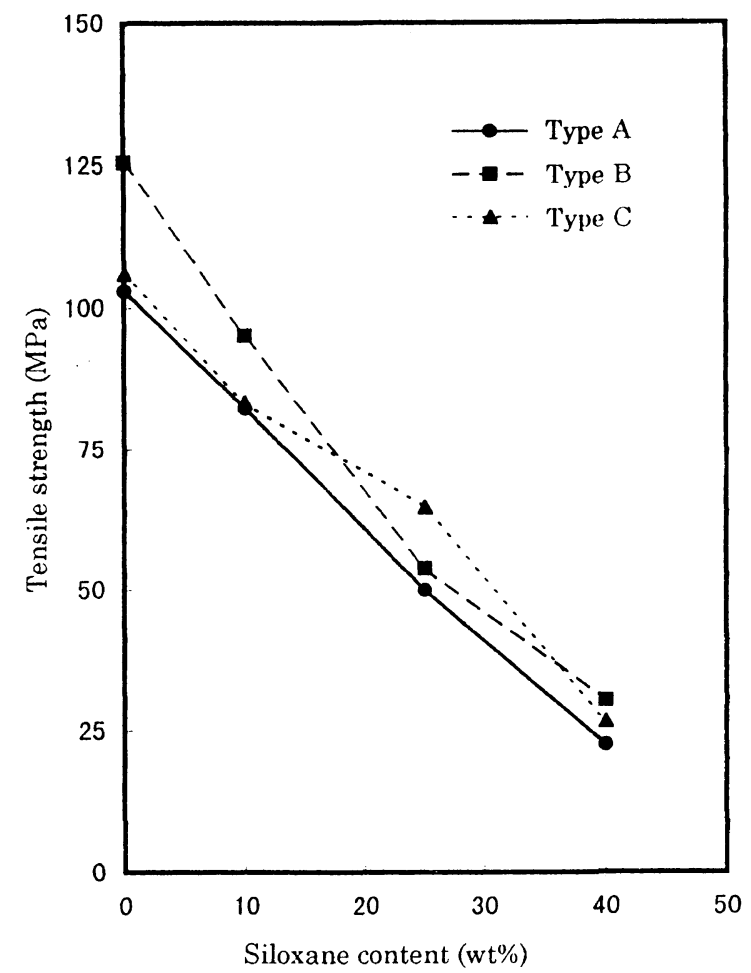

Figure 5. Relationship between tensile strength and siloxane content.

the polyimide without siloxane moiety at about $250^{\circ} \mathrm{C}$. The peaks in the $E^{\prime \prime}$ and $\tan \delta$ observed at 200 to $250^{\circ} \mathrm{C}$, where the values of $E^{\prime}$ were suddenly decreased in the corresponding $E^{\prime}$ curves, are assigned to a primary dispersion of the polyimide phase. The primary dispersion temperature of the polyimide phase was decreased and the width of the peak was broadened with the increase of siloxane content. On the other hand, the $E^{\prime \prime}$ and $\tan \delta$ peaks at about $-120^{\circ} \mathrm{C}$, which correspond to primary

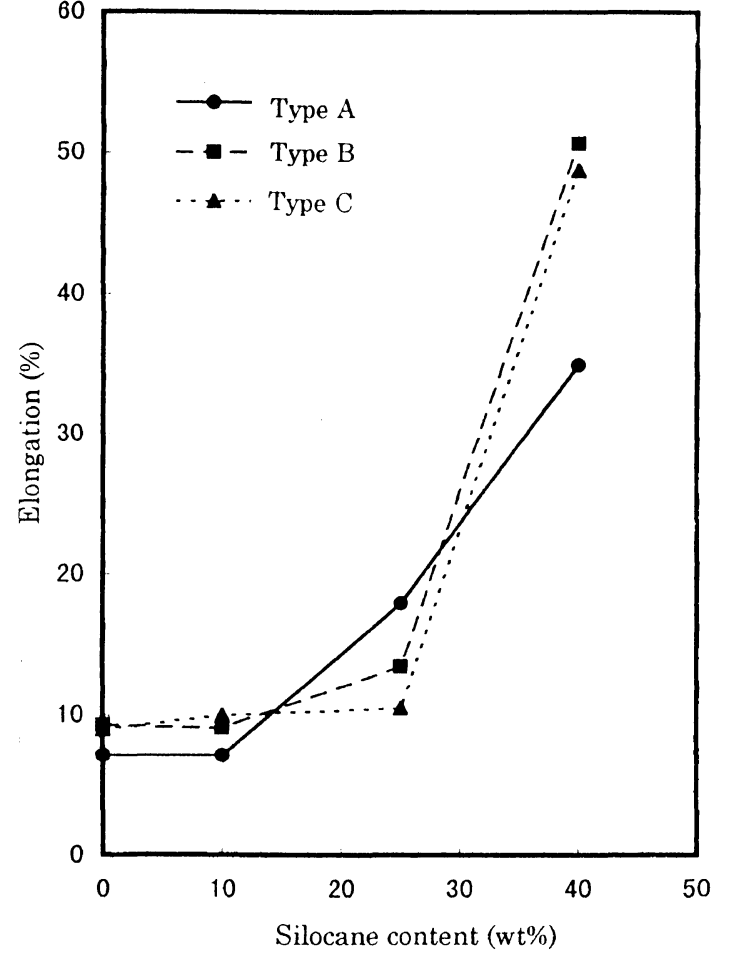

Figure 6. Relationship between elongation and siloxane content.
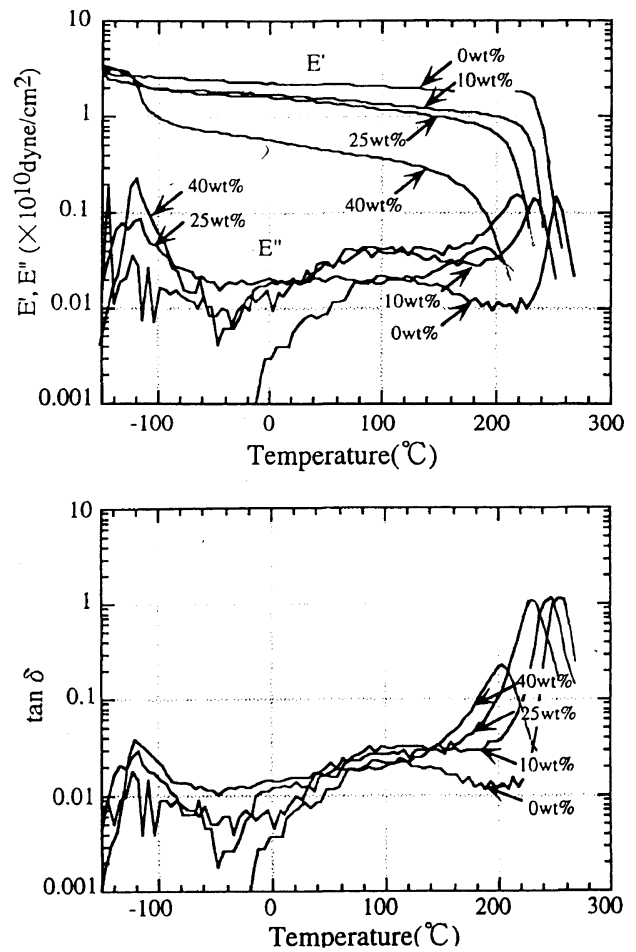

Figure 7. Temperature dependence of storage modulus $\left(E^{\prime}\right)$, loss modulus $\left(E^{\prime \prime}\right)$ and loss tangent $(\tan \delta)$ at a frequency of $10 \mathrm{~Hz}$ for siloxane-imide block copolymers.

dispersion of the siloxane phase, were almost independent of the siloxane content. These results show that siloxane dissolves in the polyimide phase to some content with the increase of siloxane content. The fact is obvious proof that siloxane-imide block copolymers consist mainly of a microphase separated structure of polyimide and siloxane phases. The values of $E^{\prime}$ were gradually de- 


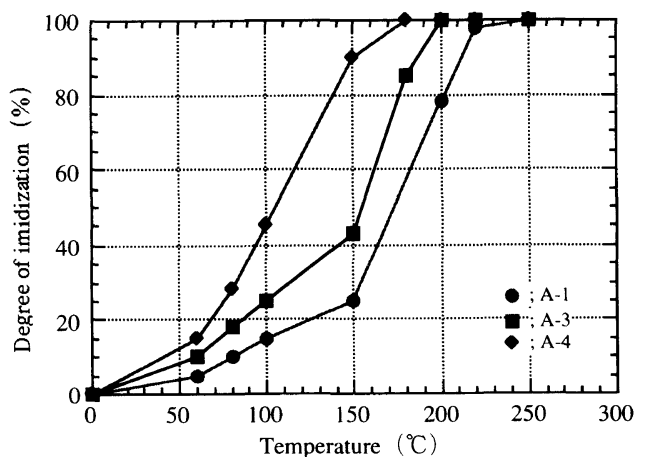

Figure 8. Dependence of imidization degree of copolyamic acid (Type A) on curing temperature

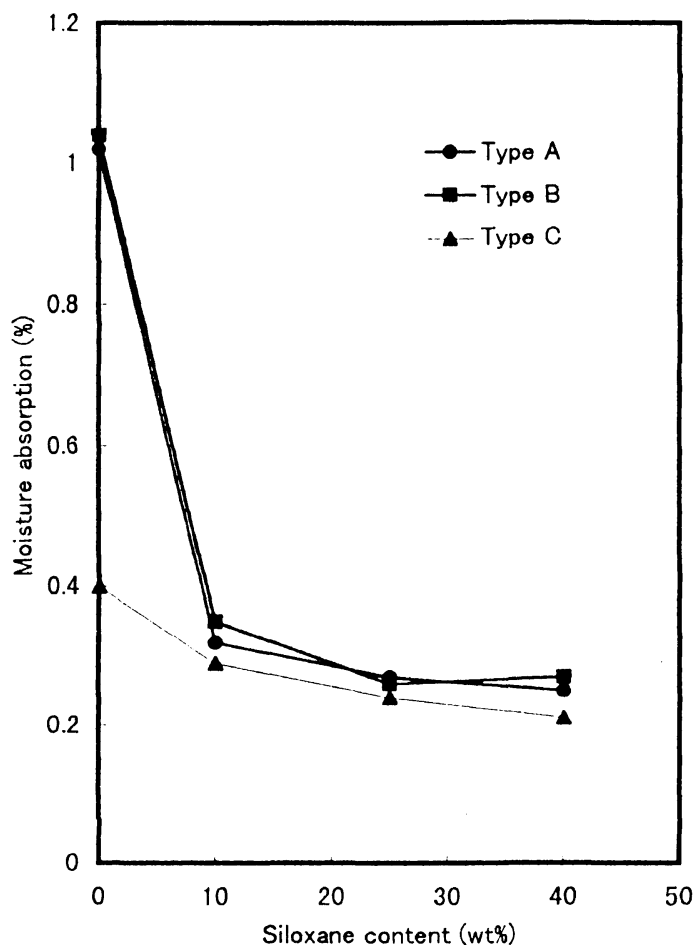

Figure 9. Relationship between moisture absorption and siloxane content.

creased with the increase of siloxane content.

\section{Imidization}

The dependence of imidization degree of polyamic acid on the final curing temperature for Type A copolymers was shown in Figure 8. The degree of imidization was estimated by the absorption peak at $1780 \mathrm{~cm}^{-1}$ after curing the polyamic acid film for one hour for each polymer. The final and the degree of imidization temperatures for Type A copolymers were lowered with the increase of siloxane content, and similar results were obtained in Types B and C copolymers. The imidization was completed at $250^{\circ} \mathrm{C}$ for $\mathrm{A}-1,200^{\circ} \mathrm{C}$ for $\mathrm{A}-3$, and $180^{\circ} \mathrm{C}$ for $\mathrm{A}-4$, respectively. The changes in degree of imidization at curing temperature shown in Figure 8 indicate that imidization of aliphatic-imide structure $\left(=\mathrm{N}-\mathrm{CH}_{2}-\right)$ easily occurred at lower temperature than that of aromatic-imide structure $(=\mathrm{N}-\mathrm{C}($ phenyl $))$, and that this order corresponds to that of $T_{\mathrm{g} 2}$ of the copolymers. $^{22}$

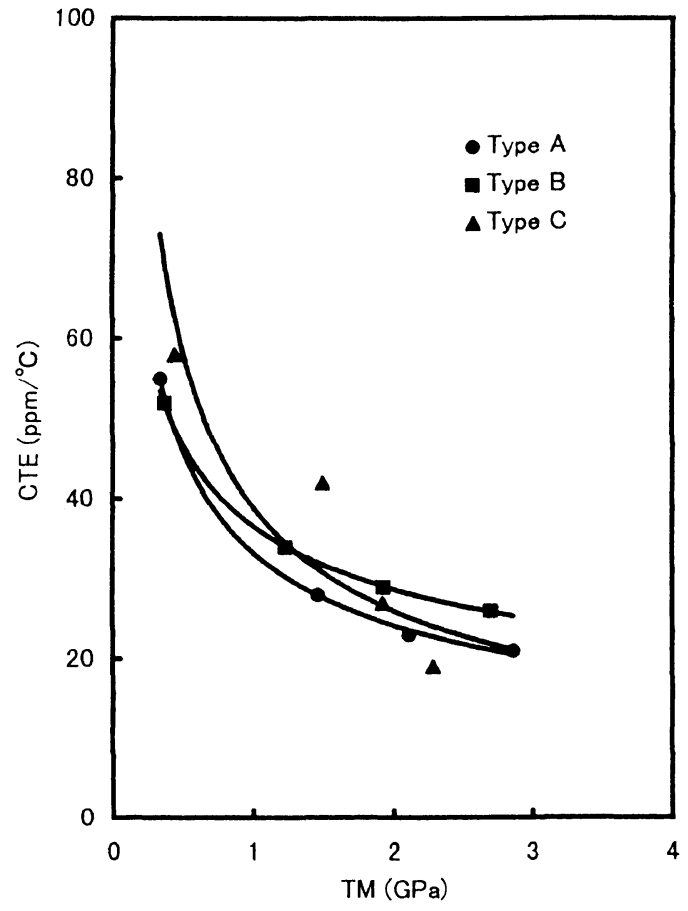

Figure 10. Relationship between thermal expansion coefficient and tensile modulus (temperature range, 25 to $100^{\circ} \mathrm{C}$ ).

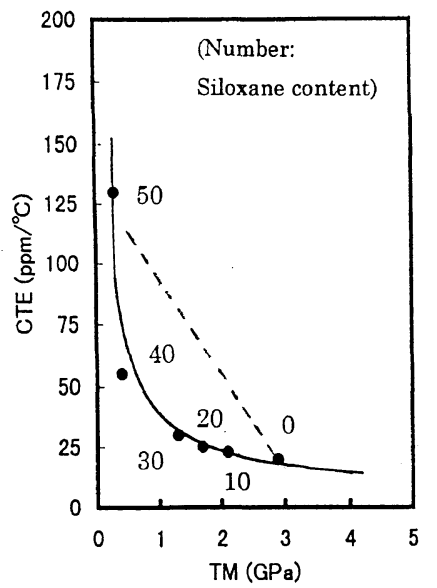

Figure 11. Relationship between thermal expansion coefficient and tensile modulus for Type A copolymers with various siloxane contents (temperature range, 25 to $100^{\circ} \mathrm{C}$ ).

\section{Moisture Absorption}

The dependence of the moisture absorption for the copolymers was shown in Figure 9. The moisture absorption of siloxane-imide block copolymers was very low compared with aromatic polyimides but almost independent of the siloxane content. This lower moisture absorption of the siloxane-imide block copolymer is interpreted in relation with the surface structure of the copolymer as well as the hydrophobic nature of dimethyl siloxane group. We also reported that siloxane phase was concentrated at the surface area in the siloxaneimide block copolymer. ${ }^{20,23}$ This siloxane-enriched surface structure is expected to protect water absorption into the polymer. Polyimide $(\mathrm{C}-1)$ showed relatively low moisture absorption compared with corresponding polyimides (A-1 and B-1) ${ }^{24}$ Especially, the copolymers with fluorine and siloxane (Type C) showed lower mois- 
Table IV. Glass transition temperatures of siloxane-imide block copolymers with various siloxane lengths

\begin{tabular}{llcc}
\hline & \multicolumn{2}{c}{ Glass transition temperature $/{ }^{\circ} \mathrm{C}^{\mathrm{b}}$} \\
\cline { 3 - 4 } Siloxane monomer ${ }^{\mathrm{a}}$ & \multicolumn{2}{c}{$T_{\mathrm{g} 1}$} & $T_{\mathrm{g} 2}$ \\
\hline None & & nd & 242 \\
GAPD & $(n=1)$ & nd & 191 \\
PSX-750 & $(n=8)$ & -118 & 216 \\
PSX-944 $\quad(n=11)$ & -122 & 220 \\
PSX-1300 $(n=15)$ & -123 & 231 \\
PSX-2560 $(n=32)$ & -124 & 237 \\
PSX-4000 $(n=45)$ & -125 & 240 \\
\hline
\end{tabular}

${ }^{\text {a }}$ Siloxane content of the copolymers, $10 \mathrm{wt} \%$. ${ }^{\mathrm{b}}$ Glass transition temperature was determined by dynamic mechanical analyzer (DMA).

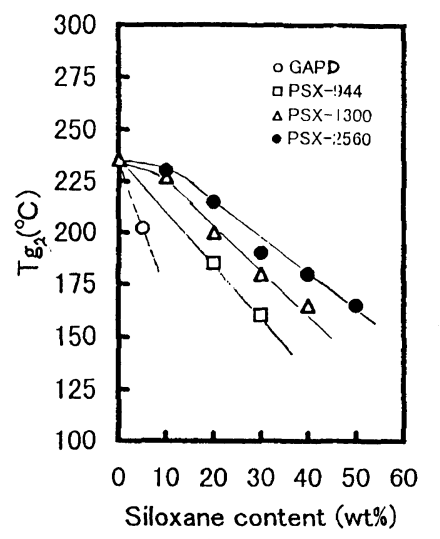

Figure 12. Dependence of siloxane content and length on glass transition temperature $\left(T_{\mathrm{g} 2}\right)$ (determined by TMA).

ture absorption than those of Type A and Type B because of the hydrophobic nature of hexafluoroisopropylidene group as well as dimethyl siloxane group.

\section{Relation Between CTE and TM}

The relation between CTE and TM of the copolymers with defferent siloxane content was shown in Figures 10 and 11. CTEs of the copolymers did not significantly increase but TMs of the copolymers decreased with increasing the siloxane content up to $30 \mathrm{wt} \%$ of siloxane content. On the other hand, CTEs of the copolymers with more than $30 \mathrm{wt} \%$ of siloxane content dramatically increased with increasing the siloxane content, but TMs of the copolymers were almost the same. In random copolymers and the coplymer with GAPD which do not show phase separation, CTEs linearly increase but TMs decrease with increasing the siloxane content of the copolymers, the relation of which is almost linear (see Figures 11 and 14). The relation between CTE and TM in random copolymers and the copolymer with GAPD is much different from that in block copolymers with microphase separated structure. This means that copolyimides with low CTEs and controlled TMs can be prepared by siloxane-imide block copolymers with microphase separated structure, which would be very useful for microelectronic coatings application due to stress relaxation from the substrates as well as good adhesion properties as reported. ${ }^{20,25}$

\section{Influence of Siloxane Length}

The influences of siloxane lengths in the copolymers

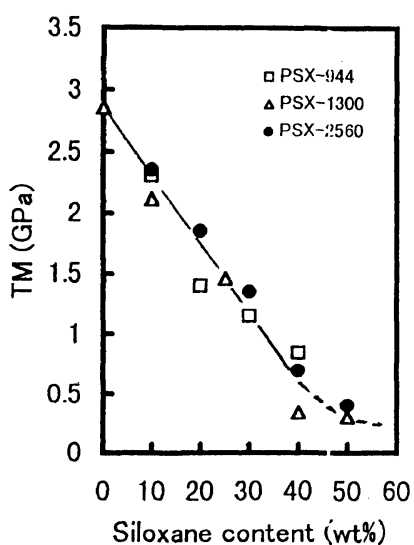

Figure 13. Dependence of siloxane content and length on tensile modulus.

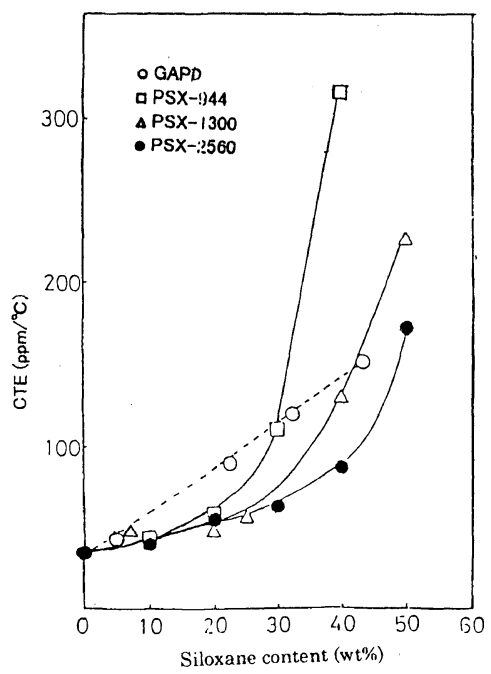

Figure 14. Dependence of siloxane content and length on thermal expansion coefficient.

based on BTDA, BAPP, and siloxane containing diamines with different siloxane lengths were also studied. Glass transition temperature $\left(T_{\mathrm{g}}\right)$ of the copolymers with different siloxane contents and lengths were summarized in Table IV and Figure 12. The $T_{\mathrm{g} 2}$ of the copolymers with same siloxane content $(10 \mathrm{wt} \%)$ rose with lengthening the siloxane length, while $T_{\mathrm{g} 1}$ was independent of the siloxane length. No $T_{\mathrm{g} 1}$ was shown in the copolymer from GAPD and the $T_{\mathrm{g} 2}$ of the copolymer from GAPD highly dropped by about $50^{\circ} \mathrm{C}$, while $T_{\mathrm{g} 2}$ from PSX-4000 was almost the same as that of polyimide without siloxane moiety. This indicates that the interaction between siloxane phase with short siloxane length and polyimide phase occurs more highly than that of longer siloxane length, that is, siloxane phase with short siloxane length dissolved in the polyimide phase to more extent than longer siloxane length. The copolymer from GAPD does not consist of microphase separated structure but consists of miscible structure of polyimide and siloxane phases.

The effect of siloxane contents and lengths in the copolymers on TM and CTE were shown in Figures 13 and 14. The CTEs of the copolymers with different siloxane contents and lengths except GAPD showed the almost same result as $T_{\mathrm{gs}}$. The CTE of the co- 
polymer from GAPD, however, linearly increased with the increase of the siloxane content. The result can be explained as same as $T_{\mathrm{g} 2}$ relating to interaction between siloxane phase and polyimide phase arising from the differences between microphase separated structure for the copolymers from PSX and miscible structure for the copolymer from GAPD. In contrast, the significant difference was not observed in the relation between TM and siloxane length.

\section{CONCLUSION}

Siloxane-imide block copolymers consist of a microphase separated structure of polyimide and polysiloxane phases, and have both properties of polyimide and polysiloxane. The copolymers have two glass transition temperatures arising from polyimide and polysiloxane phases. The higher glass transition temperature $\left(T_{\mathrm{g} 2}\right)$ of the copolymer was lowered with increasing the siloxane content, while the lower glass transition temperature $\left(T_{\mathrm{g} 1}\right)$ was almost independent of the siloxane content and length. The thermal decomposition temperature, tensile modulus and tensile strength of the copolymer were also lowered, while the elongation of the copolymer was lengthened with increasing the siloxane content. The imidization of the copolyamic acid easily occurred at lower temperature according to the increase of siloxane content. The moisture absorption of the copolymers was very low compared with the aromatic polyimides, which was almost independent of the siloxane content more than $10 \mathrm{wt} \%$. The thermal expansion coefficient of the copolymer was a little increased with increasing the siloxane content up to $30 \mathrm{wt} \%$. It is concluded that the properties of siloxane-imide block copolymers retaining both properties of polyimide and polysiloxane can be controlled by the siloxane content and length.

\section{REFERENCES}

1. K. L. Mittal, Ed, "Polyimides: Synthesis, Characterization, and Applications," Vols. 1 and 2, Plenum, New York, N.Y., 1984.
2. M. I. Bessonov, M. M. Koton, V. V. Kudryavtsev, and L. A. Laius, "Polyimides: Thermally Stable Polymers," Plenum, New York, N.Y., 1987.

3. D. Wilson, H. D. Stenzenberger, and P. Hergenrother, Ed, "Polyimides," Chapman \& Hall, New York, N.Y., 1990.

4. K. Tanaka, H. Kita, and K. Okamoto, Kobunshi Ronbunshu, 47, 945 (1990).

5. M. K. Ghosh and K. L. Mittal, Ed, "Polyimides: Fundamentals and Applications," Marcel Dekker, New York, N.Y., 1996.

6. Du Pont, Hitachi Chemical, Toshiba Chemical, and Shin-Etsu Chemical' Catalogs and Technical Information.

7. M. Fujimoto, J. Adhesive Soc. Japan, 27, 22 (1991).

8. K. Ito, Ed., "Silicone Handbook," Nikkan Kogyo Shinbun-Sha, Tokyo, 1990.

9. D. Terumuma and J. Hasegawa, Polymer Applications, 45, 558 (1996).

10. C. J. Lee, 32nd International SAMPE Symposium, April, 1987, p 576.

11. C. A. Arnold, J. D. Summers, Y. P. Chen, D. H. Chen, J. D. Graybeal, and J. E. McGrath, 33rd International SAMPE Symposium, March, 1988, p 960.

12. P. Policastro, J. H. Lupinski, and P. K. Hernandes, American Chemical Society Symp. Ser., Chapter 12, p 140.

13. J. D. Summers, C. A. Arnold, and J. E. McGrath, "Modern Plastics," April, 1989, p 126.

14. M. Ghadie, E. Zimonyi, and J. Nagy, Periodica Polytechnica Ser. Chem. Eng., 36, 249, 259 (1992).

15. S. Okinoshima, Denshizairyo (Electronic Parts and Materials), No. 11, 66 (1993)

16. H. Inoue, S. Takabayashi, T. Matsumura, T. Funakoshi, and K. Sonoyama, J. Adhesion Soc. Japan, 32, 399 (1996).

17. Y. Yamada and N. Furukawa, Preprints, 1st Pacific Polymer Conference, Vol. 1, 1989, p 201.

18. Y. Yamada, N. Furukawa, K. Wada, Y. Tsujita, and A. Takizawa, Advances in Polyimide Science and Technology, 482 (1993).

19. N. Furukawa and Y. Yamada, J. Adhesion Soc. Japan, 31, 438 (1995).

20. Y. Yamada, M. Yuasa, and N. Furukawa, J. Adhesion Soc. Japan, 32, 346 (1996).

21. Y. Yamada, N. Furukawa, and Y. Kimura, Polymer Applications, 46, 50 (1997).

22. P. Geldermans, C. Goldsmith, and F. Bedetti, "Polyimides, K. L. Mittal, Ed., Vol. 2, Plenum, New York, N.Y., 1984, p 715.

23. N. Furukawa, Y. Yamada, M. Furukawa, M. Yuasa, and Y. Kimura, J. Polym. Sci., Part A, Polym. Chem., 35, 2239 (1997).

24. S. Sasaki and S. Nishi, in "Polyimides," M. K. Ghosh and K. L. Mittal, Ed., Marcel Dekker, New York, N.Y., 1996, p 71.

25. N. Furukawa, Y. Yamada, and Y. Kimura, High Performance Polymer, 8, 617 (1996) 